\title{
Menkes disease - a case report and literature review
}

\author{
Maria Mazur-Tylki', Antoni Pyrkosz², Artur Mazur ${ }^{1}$ \\ 'Department of Paediatrics, Paediatric Endocrinology, and Diabetes, Faculty of Medicine, University of Rzeszow, \\ Rzeszow, Poland \\ ${ }^{2}$ Department of Medical Genetics, Faculty of Medicine, University of Rzeszow, Rzeszow, Poland
}

\section{ABSTRACT}

Menkes disease, also known as "kinky hair disease", is a progressive neurodegenerative disorder, which is connected with disturbances of copper absorption. The disease is caused by the disability or lack of function of the copper transporting protein (type $\mathrm{P}$ of ATPase), which is normally responsible for the maintenance of an appropriate level of copper in the serum (there is a mutation of ATP7A gene, which is located on the locus Xq13.3). This results in the excessive accumulation of copper in the intestinal wall, proximal renal tubular, pancreas, skeletal muscles, and placenta, as well as its deficiency in brain cells, liver, and connective tissue cells. The copper taken with food is not absorbed from the gastrointestinal tract.

\section{KEY WORDS:}

Menkes disease, child, case report.

\section{INTRODUCTION}

Menkes disease, also known as "kinky hair disease", is a progressive neurodegenerative disorder, which is connected with disturbances of copper absorption. The disease is caused by the disability or lack of function of the copper transporting protein (type P of ATPase), which is normally responsible for the maintenance of an appropriate level of copper in the serum (there is a mutation of ATP7A gene, which is located on the locus Xq13.3). This results in the excessive accumulation of copper in the intestinal wall, proximal renal tubular, pancreas, skeletal muscles, and placenta, as well as its deficiency in brain cells, liver, and connective tissue cells. The copper taken with food is not absorbed from the gastrointestinal tract.

\section{THE MEDICAL CASE REPORT}

A male infant was transferred to the Neonatal Intensive Care Unit on the fifth day of his life due to in- creasing respiratory failure and circulatory insufficiency. Additionally, jaundice requiring the use of continuous phototherapy was diagnosed. During the hospitalisation the medical team found also subperiosteal haematoma and made a diagnosis of urinary tract infection. After 10 days of intensive treatment the baby's health condition had improved and the he was discharged home. The child's physical and psychomotor development with generalised laxity was delayed, which was the reason for a neurological and genetic consultation in the fifth month of the baby's life. The examination revealed a light complexion, relatively loose skin, rare matt stiff and twisted hair, reduced muscle tone, laxity of ligaments, and specific features of the morphological phenotype in the form of a high forehead with clearly marked frontal bossing, full and slightly drooping cheeks, relatively small nose, quite a long nasal gullet, slightly open lips with falling corners, and small jaw. Body cooling (lability of thermoregulation), which appeared quite quickly, was diagnosed. The combination of clinical features suggest-

\section{ADDRESS FOR CORRESPONDENCE:}

Artur Mazur, Department of Paediatrics, Paediatric Endocrinology, and Diabetes, University of Rzeszow,

Rejtana 16c Ave, 35-959 Rzeszow, Poland, ORCID: 0000-0001-5393-3515, e-mail: drmazur@poczta.onet.pl 
ed Menkes disease - with such a strong suspicion at the eighth month of his life that the baby was admitted to the Paediatric, Nutrition, and Metabolic Disease Ward of the Children's Memorial Health Institute in Warsaw for further diagnostics and to determine the definitive diagnosis of the disease. Additional laboratory tests showed an increased platelet count to $462,000 / \mathrm{ul}$, hypermagnesaemia $(1.02 \mathrm{mmol} / \mathrm{l})$, slightly elevated fT3 (3.55 pg/ml), leucocyturia and bacteriuria, acid-base disturbances ( $\mathrm{pH}$ : 7.277; $\mathrm{pCO}_{2}: 44.7 \mathrm{~mm} \mathrm{Hg} ; \mathrm{HCO}_{3}$ : $13.0 \mathrm{mmol} / \mathrm{l}$; BE: $-5.4 \mathrm{mmol} / \mathrm{l})$, reduced copper level in serum $(226.0 \mathrm{ug} / \mathrm{l})$, and ceruloplasmin $(0.06 \mathrm{~g} / \mathrm{l})$. The microscopic assessment of the hair structure revealed characteristic structural changes like "pili torti", typical for Menkes disease. The molecular analysis of the ATPase7A gene (ATP7A) with the use of the next-generation sequencing technique (NGS) showed the hemizygosity of the proband - the molecular variant c. $1946+4 \mathrm{~A}>\mathrm{G}$. The clinical significance of changes of ATP7A gene (loci Xq21.1; MIM 300011) is associated not only with Menkes disease but also with the phenotype of distal spinal muscular atrophy type 3 (spinal muscular atrophy, distal, X-linked 3 - MIM 300489) and occipital horn syndrome (occipital horn syndrome - MIM 304150), which are both inherited in an X-linked recessive pattern. On the basis of the whole clinical picture, including the results of biochemical tests (reduced concentration of copper and ceruloplasmin) and the result of molecular testing, the boy was diagnosed with Menkes disease (Fig. 1).

\section{ETIOLOGY}

The clinical symptoms of the disease are connected with decreased activity of the copper enzymes that participate in oxidative reactions. Dopamine monooxygenase deficiency is associated with thermoregulatory disorders, hypoglycaemia, and disorders of the sympathetic nervous system; the reduced activity of the cytochrome c oxidase is responsible for hypotonia, hypothermia, and myelination 's disorders; the lack of lysine oxidase leads to the appearance of intestinal polyps or diverticula of the gastrointestinal tract; there are also characteristic disorders of the connective tissue (for example tortuous blood vessels); the deficiency of the peptidyl glycine monooxygenase corresponds to the phenotype of Menkes disease [2-4].

\section{EPIDEMIOLOGY}

The general incidence of Menkes disease in the world ranges from $1: 40,000$ to $1: 350,000$; in Europe this disease is diagnosed with a frequency from $1: 100,000$ to $1: 300,000$ live birth rates; while in Australia the birth incidence is much higher - approximately from $1: 50,000$ to $1: 100,000[5,6]$. It is inherited in a recessive sex-linked pattern. Therefore, Menkes disease is more often mani-

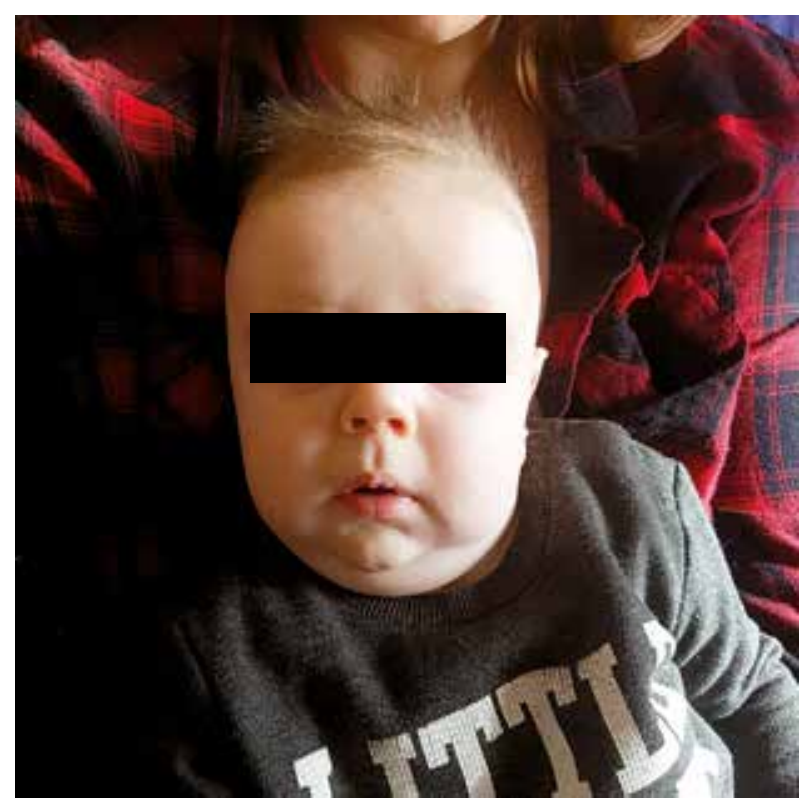

FIGURE 1. A child diagnosed with Menkes disease (own collection)

fested in the male sex; while women are usually asymptomatic carriers of the mutation, sometimes with subtle features of the clinical manifestation (such as pale complexion, specific character of the hair). The likelihood of transmission of the mutation to offspring is $50 \%$. The full phenotypic expression of the disease is observed with a frequency of $50 \%$ in male offspring. About $1 / 3$ of boys with the condition are diagnosed with the sporadic mutation arising de novo or as the result of mosaicism in the mother's germinal cells [7].

\section{CLINICAL SYMPTOMS}

In the classic form of the disease, which occurs among $15 \%$ of patients, there is a complete lack of ATP7A gene function. The majority of children are born at term in a good general condition. Occasionally some of them have a subperiosteal haematoma or spontaneous fractures. First symptoms, such as thermoregulatory disorders, prolonged jaundice, feeding difficulties, hypoglycaemia, and generalised laxity, can occur in the early neonatal period. The classic form of a disease is usually characterised by the proper development of the child up to the third month of life. After this period a delay of psychomotor development, regression of the acquired skills, seizures, motor dysfunction, blurred vision, pale and overly sulphurous skin, dysmorphic features such as depressed nasal bridge, ptosis, drooping cheeks, convex frontal bones, micrognathia, frizzy sparse eyebrows with poor pigmentation, and poor facial expressions may be observed. Inguinal or umbilical hernias and delayed eruption of teeth are often reported. During this disease thorax deformations may appear (most often the pectus excavatum), diarrhoea, vomiting, emphysema, bladder defects (including bladder diverticulum), and retinal degeneration [8-10]. In 


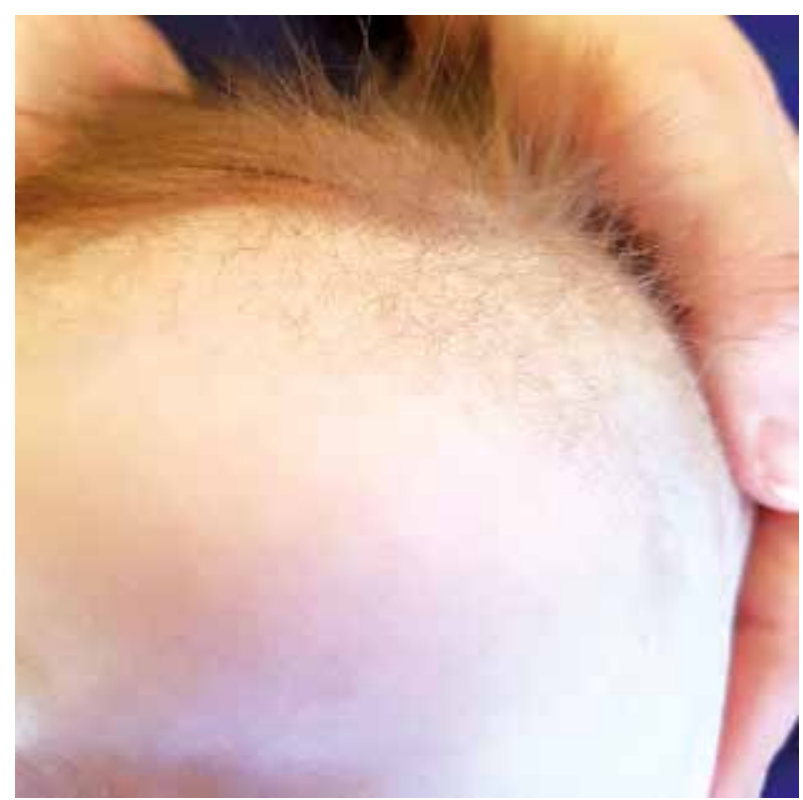

FIGURE 2. Abnormal structure of scalp hair in Menkes disease (own collection)

the classic form of Menkes disease the most significant feature is the abnormal structure of scalp hair - such as frizz, rough, sparse, dull, steel or whitish colour hair with a tendency to be fragile (Fig. 2) [11].

\section{CLINICAL FORMS OF THE DISEASE}

Three clinical variants of Menkes disease are known: classic (description above), mild form, and occipital horn syndrome (OHS). In the two above forms of Menkes disease (a mild form and OHS), there is only partial loss of gene function [3].

For the mild form of Menkes disease it is characteristic to have less neurological disability compared to the classic form. It can result also in a slight psychomotor delay, a weakness of muscle strength, a loss of muscle control, muscle twitches (tremor), involuntary a muscle movements of the head, and an abnormal structure of hair. Also, variable connective tissue changes are often reported. The patients may suffer from seizure episodes, which usually appear in later childhood. People affected by this form of Menkes disease are able to move independently and have no difficulty in speaking [8].

Occipital horn syndrome, formerly classified as type IX Ehlers-Danlos syndrome or cutis laxa X-linked, is characterised by connective tissue abnormalities including the excessive flexibility of skin and joints, abdominal hernia, diverticula of the digestive tract or the bladder, and aortic aneurysms. The patients have thermoregulatory disorders, fainting, and orthostatic hypotension. Radiographs show calcifications (known as occipital horns) within the sternocleidomastoid muscle, which are often palpable. For patients with OHS the survival is longer $[10,12]$.

\section{DIAGNOSTIC METHODS}

The basic diagnostic tests in children with suspected Menkes syndrome are an indication of the level of copper and ceruloplasmin in the serum, which is always reduced in this disease [13]. It is worth noting that in healthy children up to six months of age lower levels of these substances are reported, which may incorrectly suggest a diagnosis of Menkes disease. In Menkes syndrome the level of the serum copper is about 0-60 ug/dl and ceruloplasmin is approximately $30-50 \mathrm{mg} / \mathrm{dl}$ (in healthy children under six months of age the copper level is within the limits $20-70 \mathrm{ug} / \mathrm{dl}$ and about 70-150 ug/dl in children over six months of age); for ceruloplasmin the concentration is $50-220 \mathrm{mg} / \mathrm{dl}$ (in healthy children under six months of age) and within the limits of $200-450 \mathrm{mg} / \mathrm{dl}$ (in children over six months of age) [8].

The analysis of plasma catecholamines and target $A T$ $P 7 A$ mutation may be the best diagnostic test, which may confirm the disease before the symptoms of damage to the central nervous system occur, (the level deficiency of catecholamines is caused by reduced activity of beta-3-hydroxylase dopamine and lysine oxidase) [14].

Radiographs show typical features for osteoporosis and also metaphyseal flaring, periosteal reaction, diaphyseal periosteal thinning, and Wormian bones in the cranial sutures $[15,16]$.

Through magnetic resonance imaging (MRI), changes in the white matter of the brain can be found: rapidly progressing atrophy of the brain and cerebellar with an enlarged brain compartment [17]. Tortuous blood vessels can be also observed [11].

In the microscopic analysis of the hair structure there are pathognomonic changes, such as:

- pili torti - hair twisted 180 degrees,

- trichorrhexis - appearing in equal intervals, transverse fracture of the hair structure,

- moniletrix - hair with variable diameter of cross-section,

- trichoptilosis - longitudinal hair splitting [10].

\section{FINAL DIAGNOSIS}

The characteristic clinical picture and biochemical tests (like level of serum copper and ceruloplasmin) may generally indicate kinky hair disease.

The definitive diagnosis of Menkes disease is based on molecular genetic testing carried out by using the PCR method, which can detect the mutation in the ATP7A gene [8].

\section{DIFFERENTIATION}

Differential diagnostics should include biotinidase deficiency, aminoaciduria, Wilson's disease, Ehlers-Danlos syndrome, Marfan syndrome, mitochondrial disorders, 
osteogenesis imperfecta, and child abuse (because of the subdural haematoma and the bone fracture) [5].

In the literature there $\mathrm{X}$-linked distal neuropathy is also described, caused by the mutation of the ATP7A gene, which usually reveals itself in the second or third decade of life. The clinical picture of this disease is characterised by weakening of the muscular strength of the hands and feet with subsequent muscle atrophy, which results in foot dropping, wading gait with the loss of feeling in the fingers and toes [18].

\section{TREATMENT}

The treatment of children suffering from Menkes disease is mainly symptomatic; it is based on the daily supply of copper preparations in subcutaneous or intravenous injections so that the deficiencies of copper in the body were supplemented (oral use is not permitted because the copper becomes trapped in the intestines) [11]. The treatment aims to achieve a serum copper level within limits 70-150 mg/dl. However, despite this concentration, the copper compounds may accumulate in the duodenum, kidneys, and pancreas. Gastrostomy is often necessary for nourishment. Early implementation of the treatment (preferably in the first 10 days of life) is intended to inhibit or delay changes in the central nervous system [8].

\section{PROGNOSIS}

Most children die before the age of four years, most often due to respiratory failure. However, early implementation of the appropriate treatment may slightly the extend life span $[8,14]$.

\section{DISCLOSURE}

The authors declare no conflict of interest.

\section{REFERENCES}

1. Chang CH. Menkes Disease. Medscape 2014. https://emedicine. medscape.com/article/1180460-overview (access: 24 October 2014).

2. Kaler SG. Menkes Disease and Other ATP7A-Related Phenotypes. In: Primer on the Autonomic Nervous System, Robertson D, Biaggioni I, Burnstock G, et al. (eds.). 3rd ed. Elsevier 2012; 435-437.

3. National Organization for Rare Disorders. Menkes Disease, 2008. https://rarediseases.org/rare-diseases/menkes-disease/

4. Tęcza K. Komórkowe systemy transportu miedzi. Znaczenie kliniczne. Gliwice 2014.

5. Møller LB, Tümer Z. Menkes disease. Orphanet 2011. https://www. orpha.net/consor/cgi-bin/OC_Exp.php?Expert=565

6. McKusick VA. Menkes disease. \#309400. https://www.omim.org/ entry/309400

7. Genetics Home Reference Menkes Syndrome. https://ghr.nlm.nih. gov/condition/menkes-syndrome
8. Kochanowska I, Hampel-Osipowicz E, Waloszczyk P. Choroba Menkesa - genetyczny defekt metabolizmu miedzi. Neurol Dziec 2008; 17: 63-68.

9. National Institute of Neurological Disorders and Stroke. Menkes Disease Information Page. https://www.ninds.nih.gov/disorders/ all-disorders/menkes-disease-information-page

10. Tümer Z, Møller LB. Menkes disease. Eur J Hum Genet 2010; 18: 511-518.

11. Pascual JM, Menkes JH. Menkes disease and other ATP7A disorders. In: Rosenberg's Molecular and Genetic Basis of Neurological and Psychiatric Disease, Rosenberg R, Pascual J (eds.). 5th ed. Elsevier 2015; 455-462.

12. McKusick VA. Occipital Horn Syndrome; OHS. \#304150. https:// www.omim.org/entry/304150

13. Datta AK, Ghosh T, Nayak K, Ghosh M. Menkes kinky hair disease: A case report. Cases J 2008; 1: 158.

14. Vairo FPE, Chwal BC, Perini S et al. A systematic review and evidence-based guideline for diagnosis and treatment of Menkes disease. Mol Genet Metab 2019; 126: 6-13.

15. Genetic and Rare Diseases Information Center. Menkes disease. https://rarediseases.info.nih.gov/diseases/1521/menkes-disease.

16. Jaffar AA. Sutural bones. Archived from the original on 2009-10-25.

17. Krzeptowski W, Pierzchała O, Lenartowicz M. Metabolizm miedzi oraz charakterystyka dziedzicznych zespołów chorobowych, na tle niedoboru miedzi, spowodowanych zaburzeniami aktywności białka ATP7A. Kosmos 2014; 63: 395-413.

18. Kaler SG. Inborn errors of copper metabolism. Handb Clin Neurol 2013; 113: 1745-1754. 